\title{
Polymerization and Isomerization of Oxetanes using Heteropolyacid as a Catalyst
}

\author{
By Tetsunori SogA, ${ }^{1}$ Hiroto KUDO, ${ }^{1}$ Tadatomi NISHIKUBO, ${ }^{1, *}$ and Satoshi SATO ${ }^{2}$
}

The reaction of oxetanes using heteropolyacids as catalysts was examined. The reaction of 3-ethyl-3-phenoxymethyloxetane (EPMO) was examined using commercial heteropolyacid without any treatment $\left(\mathrm{PW}_{12 \text {-com. }}\right.$ ) as a catalyst at $80{ }^{\circ} \mathrm{C}$ in chlorobenzene for $12 \mathrm{~h}$, and the cationic ring-opening polymerization of EPMO proceeded smoothly to give the corresponding polyether poly(EPMO) in $89 \%$ yield. However, no polymer was obtained using treated heteropolyacid

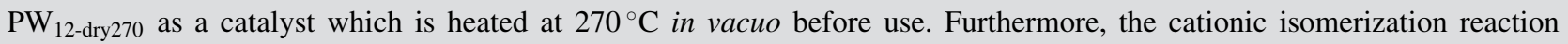
of 3-acethyloxymethyl-3-ethyloxetane (AOEO) using $\mathrm{PW}_{12 \text {-dry270 }}$ was examined to give 4-ethyl-1-methyl-2,6,7-trioxabicyclo[2.2.2]octane (BOE) in $70 \%$ yield.

KEY WORDS: Oxetane / Heteropolyacid / Catalyst / Cationic Ring-opening Polymerization / Cationic Isomerization /

Heteropolyacids (HPA's) are well-known ${ }^{1-3}$ as multifunctional catalysts in the organic chemistry and also act as solid acid catalysts for the cationic polymerization of olefins and cyclic ethers. It was reported ${ }^{4}$ that cationic polymerizations of tetrahydrofuran (THF) and 1,3,5-trioxane using HPA as a catalyst proceeded smoothly to afford the corresponding polyether and poly(oxymethylene) with high molecular weights in high yields, respectively. Aoshima et al. ${ }^{5}$ also reported that poly(THF) with narrow molecular weight distribution could be obtained using the complex of water and HPA as a catalytic system.

Meanwhile, oxetanes with 4-membered ring are wellknown $^{6-13}$ to be polymerized very smoothly with cationic catalysts due to their high basicities. Some interesting cationic reactions of oxetane using certain catalysts have been reported. Vandenberg et al. ${ }^{10}$ reported the synthesis of linear polyethers by the cationic ring-opening polymerization of 3,3-bis(hydroxymethyl)oxetane (BHO) using aluminium complexes as cationic catalysts. Hult et al. ${ }^{14}$ reported the synthesis of hyperbranched polyethers by the cationic ring-opening polymerization of 3-ethyl-3-(hydroxymethyl)oxetane (EHO) using antimonate derivative as a cationic catalyst. Penczek et al. ${ }^{15}$ also reported the synthesis of hyperbranched polyethers by the cationic ring-opening polymerization of $\mathrm{BHO}$ and the copolymerization of $\mathrm{BHO}$ and $\mathrm{EHO}$ with medium molecular weight polymers in good yields. Furthermore, Motoi et al. ${ }^{16-21}$ reported that the isomerization reaction of oxetanes containing ester groups proceeded smoothly using acid catalysts to give the corresponding bicyclo ortho esters selectively. These results indicate that the cationic reactions of oxetanes are strongly affected by the structures of oxetanes and catalysts, and the combination of oxetanes with catalysts. Chen et al. ${ }^{22}$ reported the cationic polymerization of tetrahydrofuran using oxetane as a promoter in the presence HPA as a catalyst.

However, there are no detail study concerning the cationic organic reactions of oxetanes using HPA as a catalyst. Here, we report the cationic isomerization and polymerization of certain oxetanes using 12-tungsto(IV)phosphoric acids $\left(\mathrm{PW}_{12}\right)$ as HPA catalyst.

\section{EXPERIMENTAL}

\section{Materials}

Commercial chlorobenzene was dried using $\mathrm{CaH}_{2}$ and purified by distillation before use. Reagents grade pyridine, acetic anhydride, and $\mathrm{HCl}$ were used without further purification. 12-Tungsto(IV) phosphoric acid ( $\mathrm{PW}_{12 \text {-com. }}$ ) was purchased from WAKO Co and used without further modification.

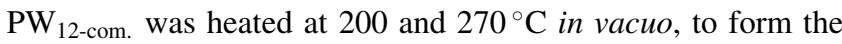
corresponding dried catalysts $\mathrm{PW}_{12 \text {-dry200 }}$ and $\mathrm{PW}_{12 \text {-dry270, }}$ respectively. 3-Ethyl-3-phenoxymethyloxetane (EPMO) and 3-ethyl-3-hydroxymethyloxetane (EHMO) (donated from Toagosei Co., Ltd.) were purified by distillation before use.

\section{Measurements}

${ }^{1} \mathrm{H}$ NMR and ${ }^{13} \mathrm{C}$ NMR spectroscopy were recorded on a JEOL Model JNM $\alpha-500\left(500 \mathrm{MHz}\right.$ for ${ }^{1} \mathrm{H}$ NMR and $125 \mathrm{MHz}$ for ${ }^{13} \mathrm{C} \mathrm{NMR}$ ) instrument in $\mathrm{CDCl}_{3}$ using $\mathrm{Me}_{4} \mathrm{Si}$ (TMS) as an internal standard. IR spectra were measured on a Jasco Model FT/IR-420 spectrometer. The number-average molecular weight $\left(M_{\mathrm{n}}\right)$ and weight-average molecular weight $\left(M_{\mathrm{w}}\right)$ of the polymers were estimated by size exclusion chromatography (SEC; TOSO model HLC-8020) on TSK gel Multipore Hx1-M columns calibrated by narrow molecular weight polystyrene standards and with THF as an eluent without correction with a refractive index detector.

\section{Synthesis of 3-Acethyloxymethyl-3-ethyloxetane (AOEO)}

AOEO was synthesized by the according to the reported method $^{23}$ as follows. Acetic anhydride $(30.6 \mathrm{~g}, 300.0 \mathrm{mmol})$ was added slowly to the solution of EHMO $(29.0 \mathrm{~g}, 250.0 \mathrm{mmol})$ and

\footnotetext{
${ }^{1}$ Department of Material and Life Chemistry, Faculty of Engineering, Kanagawa University, Rokkakubashi, Kanagawa-ku, Yokohama 221-8686, Japan ${ }^{2}$ Department of Applied Chemistry and Biotechnology, Faculty of Engineering, Chiba University, 1-33 Yayoi-cho Inage-ku, Chiba 263-8522, Japan

*To whom correspondence should be addressed (E-mail: nishikubot@kanagawa-u.ac.jp).
} 
pyridine $(23.7 \mathrm{~g}, 300.0 \mathrm{mmol})$ in $\mathrm{THF}$ at $0^{\circ} \mathrm{C}$ and stirred at room temperature for $12 \mathrm{~h}$. The reaction mixture was concentrated by a rotary evaporator. After that, ethyl acetate $(400 \mathrm{~mL})$ was added to the residues and washed following water with three times, the saturated aqueous solution of sodium hydrogen carbonate, hydrochloric acid solution $(10 \% \mathrm{v} / \mathrm{v})$, and water. The organic layer was dried over with $\mathrm{MgSO}_{4}$ and concentrated by a rotary evaporator, followed by distillation to obtain colorless liquid AOEO. $\mathrm{Bp}=72^{\circ} \mathrm{C} / 5 \mathrm{mmHg}$. Yield $=24.9 \mathrm{~g}(63 \%)$. IR (bulk, $\mathrm{cm}^{-1}$ ): 1741 ( $v \mathrm{C}=\mathrm{O}$, ester), 1241 ( $v \mathrm{C}-\mathrm{O}-\mathrm{C}$ ) and 983 ( $v \mathrm{C}-\mathrm{O}-\mathrm{C}$ cyclic ether). ${ }^{1} \mathrm{H}$ NMR $\left(500 \mathrm{MHz}, \mathrm{CDCl}_{3}, \mathrm{TMS}\right) \delta(\mathrm{ppm})=$ $0.92\left(\mathrm{t}, 3.0 \mathrm{H}, J=7.8 \mathrm{~Hz},-\mathrm{CH}_{2}-\mathrm{CH}_{3}\right), 1.76(\mathrm{q}, 2.0 \mathrm{H}, J=7.8$ $\left.\mathrm{Hz},-\mathrm{CH}_{2}-\right), 2.10\left(\mathrm{~s}, 3 \mathrm{H},-\mathrm{CH}_{3}\right), 4.21\left(\mathrm{~s}, 2 \mathrm{H},-\mathrm{O}-\mathrm{CH}_{2}-\right), 4.41,4.47$ (dd, $4 \mathrm{H}, J=6.6, J=28.0 \mathrm{~Hz},-\mathrm{O}-\mathrm{CH}_{2}$ - cyclic ether). ${ }^{13} \mathrm{C} \mathrm{NMR}$ $\left(125 \mathrm{MHz}, \mathrm{CDCl}_{3}, \mathrm{TMS}\right) \delta(\mathrm{ppm})=8.22\left(-\mathrm{CH}_{2}-\underline{\mathrm{CH}}_{3}\right), 20.92$ $\left(-\mathrm{CH}_{3}\right), 26.93\left(-\mathrm{CH}_{2}-\right), 42.64(=\mathrm{C}=), 66.46\left(-\mathrm{O}-\mathrm{CH}_{2}-\right), 77.96$ (-O-CH - cyclic ether), 171.23 ( $>\mathrm{C}=\mathrm{O}$ carbonyl carbon).

\section{Cationic Rring-Opening Polymerization of EPMO}

Typical procedure: $\mathrm{PW}_{12 \text {-com. }}(1.5 \mathrm{mg}, 0.1 \mathrm{wt} \%)$ in a polymerization tube equipped with rubber septum was degassed and substituted with nitrogen at room temperature. Chlorobenzene $(8 \mathrm{~mL})$ and EPMO $(1.54 \mathrm{~g}, 8.0 \mathrm{mmol})$ were injected by syringe and, then the solution was stirred at $80^{\circ} \mathrm{C}$ for $12 \mathrm{~h}$.

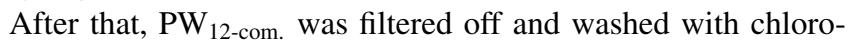
form several times. The resulting organic phase was evaporated under reduced pressure. The residual oil was poured into large amount of methanol to precipitate the colorless high viscos oily product and then dried in vacuo at $60^{\circ} \mathrm{C}$ for $24 \mathrm{~h}$ to obtain the polymer. The yield of polymer was $89 \%(1.36 \mathrm{~g}) . M_{\mathrm{n}}=14400$, $M_{\mathrm{w}} / M_{\mathrm{n}}=2.3$. IR (film, $\left.\mathrm{cm}^{-1}\right): 1598$ and $1496(v \mathrm{C}=\mathrm{C}$ of aromatic), 1243 and 1106 (v C-O-C). ${ }^{1} \mathrm{H} \mathrm{NMR}(500 \mathrm{MHz}$, $\left.\mathrm{CDCl}_{3}, \mathrm{TMS}\right) \delta(\mathrm{ppm})=0.66-0.83\left(\mathrm{~m},-\mathrm{CH}_{2}-\underline{\mathrm{CH}_{3}}\right), 1.32-1.44$ (m, $\left.-\mathrm{CH}_{2}-\mathrm{CH}_{3}\right), 3.12-3.27$ (m, $-\mathrm{CH}_{2}-\mathrm{O}-\mathrm{CH}_{2}-\mathrm{O}-$ ), $3.60-3.77$ (m, - $\left.-\overline{\mathrm{CH}_{2}} \mathrm{OPh}\right), 6.67-7.26$ (m, aromatic). ${ }^{13} \mathrm{C} \mathrm{NMR}(125 \mathrm{MHz}$, $\left.\mathrm{CDCl}_{3}, \mathrm{TMS}\right) \delta(\mathrm{ppm})=8.17\left(-\mathrm{CH}_{2}-\underline{\mathrm{CH}}_{3}\right), 23.78\left(-\mathrm{CH}_{2}-\mathrm{CH}_{3}\right)$, $43.63(>\mathrm{C}<), 69.12\left(-\underline{C H}_{2}-\mathrm{OPh}\right), 71.95\left(-\mathrm{CH}_{2}-\mathrm{O}-\mathrm{CH}_{2}-\mathrm{O}-\right)$, 114.93-159.87 (aromatic).

\section{Cationic Isomerization of AOEO}

Chlorobenzene $(8 \mathrm{~mL})$, AOEO $(1.25 \mathrm{~g}, 8.0 \mathrm{mmol})$, and $\mathrm{PW}_{12 \text {-dry270 }}(1.3 \mathrm{mg}, 0.1 \mathrm{wt} \%)$ were injected in a three-way stopcock under nitrogen by syringe, and then the solution was stirred at $80{ }^{\circ} \mathrm{C}$ for $12 \mathrm{~h}$. After that, the mixture was concentrated. The residual was purified by column chromatography on alumina using mixed solvents of $n$-hexane and ethylacetate as an eluent, followed by recrystallization from the mixed solvents of $n$-hexane and ethylacetate to obtain the colorless solid, 4-ethyl-1-methyl-2,6,7-trioxabicyclo[2.2.2]octane (BOE). ${ }^{24}$ The yield of BOE was $70 \%(0.88 \mathrm{~g})$. IR $(\mathrm{KBr}$, disk cm ${ }^{-1}$ ): 998 ( $v$ C-O-C). ${ }^{1} \mathrm{H}$ NMR (500 MHz, $\mathrm{CDCl}_{3}, \mathrm{TMS}$ ) $\delta(\mathrm{ppm})=0.81\left(\mathrm{t}, J=7.5 \mathrm{~Hz} 3.0 \mathrm{H},-\mathrm{CH}_{2}-\mathrm{CH}_{3}\right), 1.24 \quad(\mathrm{q}$, $\left.J=7.5 \mathrm{~Hz} 2.0 \mathrm{H},-\mathrm{CH}_{2}-\mathrm{CH}_{3}\right), 1.45\left(\mathrm{~s}, 3 \mathrm{H}, \equiv{\overline{\mathrm{C}-\mathrm{CH}_{3}}}_{3}, 3.92(\mathrm{~s}\right.$, $\left.6 \mathrm{H}, \mathrm{O}-\mathrm{CH}_{2}-\mathrm{C}\right) .{ }^{13} \mathrm{C} \mathrm{NMR}\left(125 \mathrm{MHz}, \mathrm{CDCl}_{3}, \mathrm{TMS}\right) \delta(\mathrm{ppm})=$ $7.31\left(-\mathrm{CH}_{2}-\mathrm{CH}_{3}\right), 22.52\left(-\mathrm{CH}_{2}-\mathrm{CH}_{3}\right), 31.22\left(-\mathrm{CH}_{3}\right), 33.13$ $(=\mathrm{C}=), 64.09\left(-\mathrm{O}-\mathrm{CH}_{2}-\right), 109.44\left(-\mathrm{C}\left(-\mathrm{O}-\mathrm{CH}_{2}-\right)_{3}\right)$.

\section{RESULT AND DISCUSSION}

\section{Preparation of 12-Tungsto (IV) Phosphoric Acid (PW 12 )}

When we examined the reaction of oxetane and commercial grade $\mathrm{PW}_{12}\left(\mathrm{PW}_{12 \text {-com. }}\right)$ in certain solvents, the good reproducibility of the resulting polymers could not be obtained. As described in the introduction, it has been reported that water was required for the cationic polymerization system of THF using HPA as a catalyst. Therefore, we considered that the values of absorbed water on HPA should be controlled. $\mathrm{PW}_{12 \text {-com. }}$ was heated at $200^{\circ} \mathrm{C}$ and $270{ }^{\circ} \mathrm{C}$ in vacuo for $8 \mathrm{~h}$ to prepare

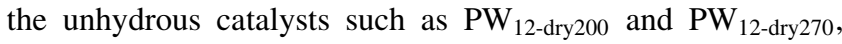
respectively. Figure 1 illustrates the IR spectra of $\mathrm{PW}_{12-c o m}$.,

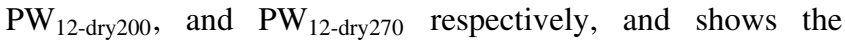
decreases of absorption peaks assignable to water around at $3500 \mathrm{~cm}^{-1}$ by heating at elevated temperatures. This suggests

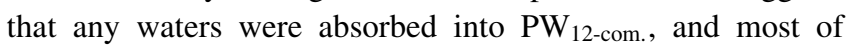
the absorbed water can be removed by heating at elevated temperature in vacuo. Then, we examined the following reaction of oxetanes using three types of $\mathrm{PW}_{12}$ such as

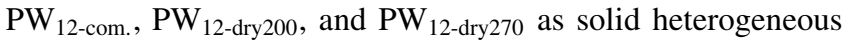
catalysts.

Cationic Ring-Opening Polymerization of Oxetane; The Reaction of EPMO using $\mathbf{P W}_{12-\text { com., }} \mathbf{P W}_{12 \text {-dry200, and }}$ PW $_{12-\text { dry270 }}$ as Catalysts

The cationic ring-opening polymerization of EPMO was performed using $0.1 \mathrm{wt} \%$ of $\mathrm{PW}_{12 \text {-com., }} \mathrm{PW}_{12 \text {-dry200, and }}$ $\mathrm{PW}_{12-\mathrm{dry} 270}$ as catalysts at various temperatures in chlorobenzene under nitrogen (Scheme 1 and Table I).

When the reaction of EPMO and $\mathrm{PW}_{12 \text {-com. }}$ was carried out in chlorobenzene at $0{ }^{\circ} \mathrm{C}$ for $12 \mathrm{~h}$, it was observed that no reaction proceeded (run 1). At room temperature for this reaction, $31 \%$ of EPMO was converted to afford the corresponding polymer with $M_{\mathrm{n}}=14200$ and $M_{\mathrm{w}} / M_{\mathrm{n}}=1.9$ in $20 \%$ yield (run 2). Furthermore, the conversions of EPMO and yields of polymers increased with increasing reaction temperatures (runs 3-5). Consequently, it was found that the cationic ring-opening polymerization of EPMO proceeded at $80^{\circ} \mathrm{C}$ quantitatively to afford the corresponding polymer with $M_{\mathrm{n}}=14400$ and $M_{\mathrm{w}} / M_{\mathrm{n}}=2.3$ in $89 \%$ yield. (Table I).

The structure of the obtained polymers was confirmed by IR and ${ }^{1} \mathrm{H}$ NMR spectroscopy. Figure 2 depicts the ${ }^{1} \mathrm{H}$ NMR spectra of obtained polymer with $M_{\mathrm{n}}=14400, M_{\mathrm{w}} / M_{\mathrm{n}}=2.3$ (run 5 in Table I) along with EPMO. Figure 2(b) shows the signals assignable to methylene and methyl protons of obtained polymer at $1.86-1.92,4.03-4.07,4.32-4.52$ and $1.35-1.41$ ppm, respectively. IR spectroscopy of the obtained polymer also supports the result of ${ }^{1} \mathrm{H}$ NMR analysis. SEC curves of the obtained polymers show unimodal peaks. These results mean that the cationic ring-opening polymerization of EPMO proceeded smoothly at $80^{\circ} \mathrm{C}$ to give the corresponding polyether poly(EPMO) in satisfactory yield. It was also found that all of the obtained polymers were soluble in common organic solvents such as chloroform and THF. 


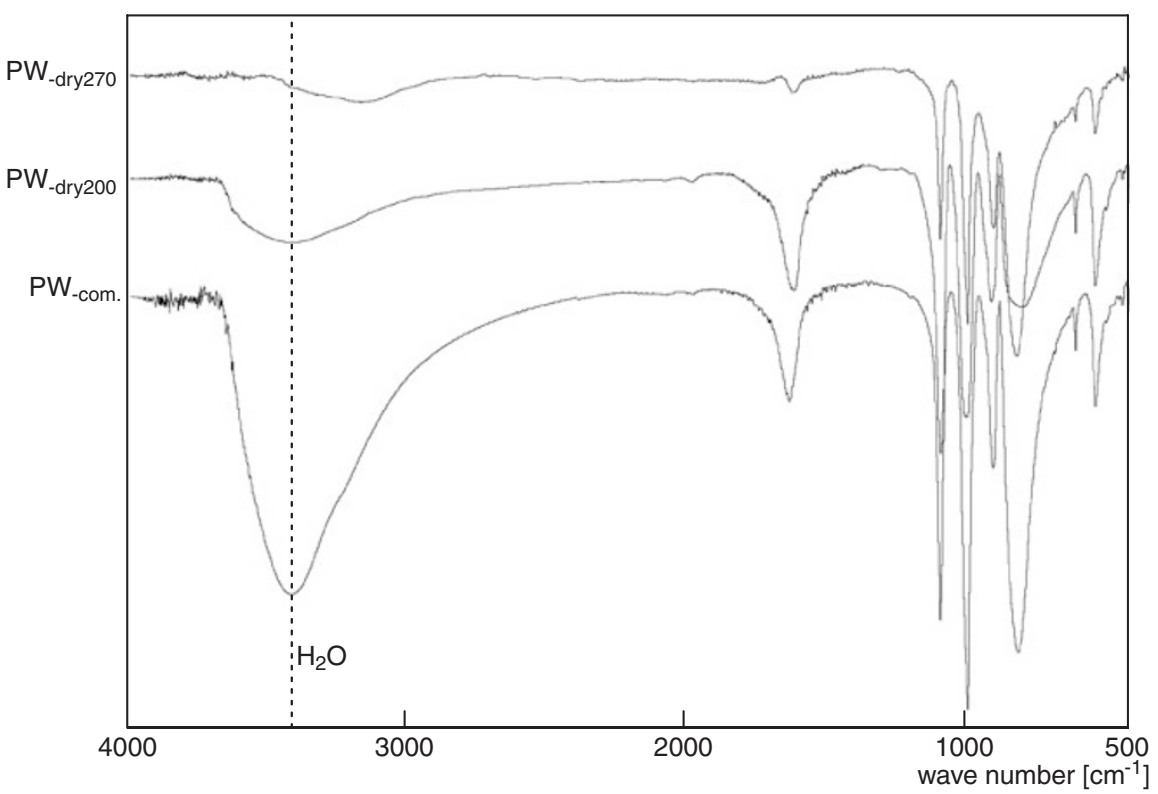

Figure 1. IR spectra of $\mathrm{PW}_{12-\text { com. }}, \mathrm{PW}_{12-\text { dry200, and }} \mathrm{PW}_{12-\text { dry270. }}$.

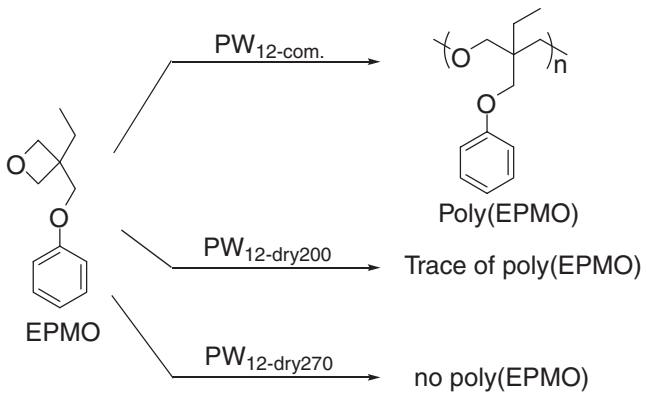

Scheme 1. The reaction of EPMO using $\mathrm{PW}_{12-c o m}, \mathrm{PW}_{12-\text { dry200, and }}$ $\mathrm{PW}_{12-\mathrm{dry} 270}$ as catalysts.

Furthermore, the cationic ring-opening polymerization of EPMO using $\mathrm{PW}_{12 \text {-dry200 }}$ and $\mathrm{PW}_{12 \text {-dry270 }}$ were examined in the same way as the case of $\mathrm{PW}_{12 \text {-com. }}$. In the case of $\mathrm{PW}_{12 \text {-dry200, }}$ only $4 \%$ of EPMO converted to give the corresponding poly(EPMO) with $M_{\mathrm{n}}=16100$ and $M_{\mathrm{w}} / M_{\mathrm{n}}=3.0$ (run 6). Furthermore, it was observed that the conversion of EPMO was trace and poly(EPMO) could not be obtained (run 7) using $\mathrm{PW}_{12 \text {-dry270 }}$ as a catalyst. These results mean that $\mathrm{PW}_{12 \text {-com. }}$ act as a heterogeneous cationic catalyst associated with absorbed water in $\mathrm{PW}_{12}$ for the polymerization of EPMO, but $\mathrm{PW}_{12 \text {-dry200 }}$ and $\mathrm{PW}_{12 \text {-dry270 }}$ could not do without associating small water. To clear the effect of water in these catalysts, we examined the cationic ring-opening polymerization of EPMO using the

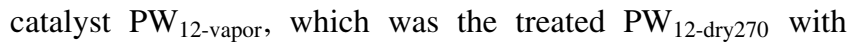
vapor, and it was found that the polymerization of EPMO proceeded to afford the corresponding poly(EPMO) with $M_{\mathrm{n}}=$ 10400 in $88 \%$ yield (run 8). That is, small water including in

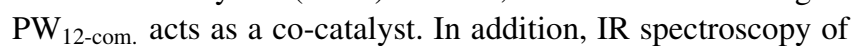
$\mathrm{PW}_{12 \text {-vapor }}$ same to that of $\mathrm{PW}_{12 \text {-com. }}$.

It is well known ${ }^{25}$ that the cationic-ring opening polymerization of oxetane was performed using certain acids such as
Table I. The reaction of EPMO using $\mathrm{PW}_{12-\text { com. }}, \mathrm{PW}_{12 \text {-dry200, }}$ and $\mathrm{PW}_{12-d y 270}$ as catalysts ${ }^{\mathrm{a}}$ )

\begin{tabular}{|c|c|c|c|c|c|c|}
\hline Run & Catalyst & $\begin{array}{c}\text { Temperature } \\
\left({ }^{\circ} \mathrm{C}\right)\end{array}$ & $\begin{array}{c}\text { Conversion }{ }^{\text {b) }} \\
(\%)\end{array}$ & $\begin{array}{c}\text { Yield }^{c)} \\
(\%)\end{array}$ & $M_{\mathrm{n}}{ }^{\mathrm{d})}$ & $M_{\mathrm{w}} / M_{\mathrm{n}}{ }^{\mathrm{d})}$ \\
\hline 1 & $\mathrm{PW}_{12-\text { com. }}$ & 0 & $<1$ & - & - & - \\
\hline 2 & $\mathrm{PW}_{12 \text {-com. }}$ & r.t. & 31 & 20 & 14200 & 1.9 \\
\hline 3 & $\mathrm{PW}_{12 \text {-com. }}$ & 40 & 77 & 66 & 14300 & 2.2 \\
\hline 4 & $\mathrm{PW}_{12 \text {-com. }}$ & 60 & $>99$ & 88 & 13900 & 2.5 \\
\hline 5 & $\mathrm{PW}_{12 \text {-com. }}$ & 80 & $>99$ & 89 & 14400 & 2.3 \\
\hline 6 & $\mathrm{PW}_{12-\mathrm{dry} 200}$ & 80 & 4 & trace & 16100 & 3.0 \\
\hline 7 & $\mathrm{PW}_{12 \text {-dry270 }}$ & 80 & $<1$ & - & - & - \\
\hline 8 & $\mathrm{PW}_{12 \text {-vapor }}$ & 80 & $>99$ & 88 & 10400 & 2.8 \\
\hline 9 & $\mathrm{BF}_{3} \cdot \mathrm{OEt}_{2}$ & 80 & 95 & 52 & 6000 & 1.7 \\
\hline 10 & $\mathrm{SnCl}_{4}$ & 80 & $<1$ & - & - & - \\
\hline 11 & $\mathrm{TfOH}$ & 80 & $<1$ & - & - & - \\
\hline 12 & $\mathrm{HClO}_{4}$ & 80 & $<1$ & - & - & - \\
\hline 13 & $\mathrm{TsOH}$ & 80 & $<1$ & - & - & - \\
\hline 14 & $\mathrm{H}_{2} \mathrm{SO}_{4}$ & 80 & $<1$ & - & - & - \\
\hline
\end{tabular}

a) The reaction conditions: EPMO $(8 \mathrm{mmol})$, catalyst $(0.1 \mathrm{wt} \%)$, in chlorobenzene $(8 \mathrm{~mL})$ for $12 \mathrm{~h} .{ }^{\text {b) }}$ Calculated by ${ }^{1} \mathrm{H}$ NMR. ${ }^{\mathrm{c}}$ Insoluble parts in methanol. d) Estimated by SEC (THF) based on polystyrene standards.

boron trifluoride diethyl ether complex $\left(\mathrm{BF}_{3} \cdot \mathrm{OEt}_{2}\right)$, tin(IV) chloride $\left(\mathrm{SnCl}_{4}\right)$, trifluoromethanesulfonic acid (TfOH), perchloric acid $\left(\mathrm{HClO}_{4}\right)$, p-toluenesulfonic acid $(\mathrm{TsOH})$, and conc. $-\mathrm{H}_{2} \mathrm{SO}_{4}$. These acids act as cationic catalysts on the ringopening polymerization of oxetanes at lower temperatures than $0{ }^{\circ} \mathrm{C}$. We re-examined the cationic polymerization of EPMO using these common acids under the same condition of $\mathrm{PW}_{12 \text {-com. }}$ as mentioned above, and it was found that only $\mathrm{BF}_{3} \cdot \mathrm{OEt}_{2}$ gave the corresponding poly(EPMO) with $M_{\mathrm{n}}=$ 6000 in $52 \%$ yield (run 9). However, the other catalysts did not produce any poly(EPMO) (runs 10-14). These mean that cationic polymerization system is strongly effect of the reaction temperature and reaction media. In general, the cationic polymerization would be performed at lower temperatures at about $0{ }^{\circ} \mathrm{C}$ to prevent the termination reaction. However, in the 


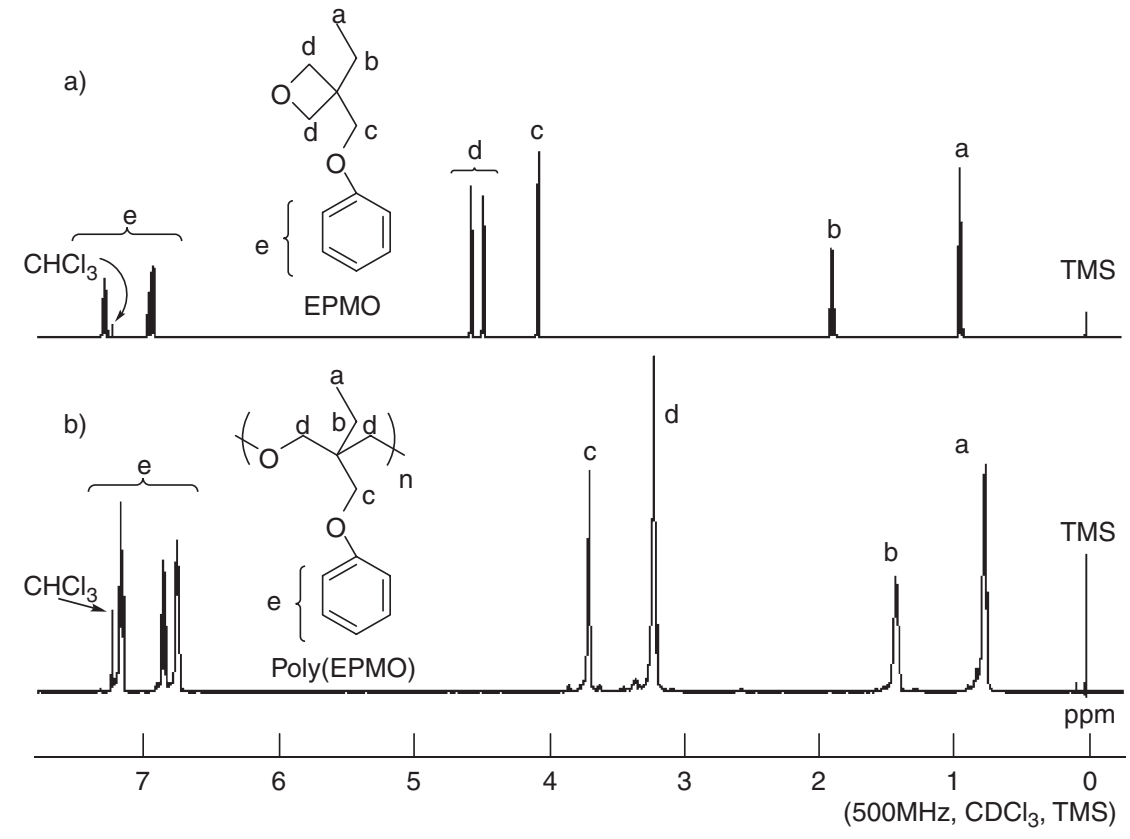

Figure 2. ${ }^{1} \mathrm{H}$ NMR spectra. a) EPMO. b) poly(EPMO), $M_{\mathrm{n}}=14400, M_{\mathrm{w}} / M_{\mathrm{n}}=2.3$ obtained by the reaction of EPMO, run 5 in Table I.

case of $\mathrm{PW}_{12-\mathrm{com}}$, the cationic polymerization did not proceed at lower temperatures in the range between $0-25^{\circ} \mathrm{C}$, and proceeded at $80^{\circ} \mathrm{C}$ to afford the corresponding polymer in satisfactory yield. That is, $\mathrm{PW}_{12 \text {-com. }}$ can act as a superior catalyst for the cationic ring-opening polymerization of oxetane at high reaction temperature.

The Restoration of Catalytic Activity of $\mathrm{PW}_{12 \text {-com. for }}$ Cationic Ring-Opening Polymerization of EPMO

Since the $\mathrm{PW}_{12 \text {-com. }}$ is insoluble in common organic solvents, in this cationic polymerization system, separation of the resulting polymers and catalysts from the reaction mixtures is very easy. Therefore, after the first polymerization, $\mathrm{PW}_{12 \text {-com. }}$ was recovered by the filtration, and washed with chloroform several times, and then dried in vacuo at room temperature for $24 \mathrm{~h}$. The resulting $\mathrm{PW}_{12 \text {-cycle }}$ was reused as a catalyst for the polymerization of EPMO at $80^{\circ} \mathrm{C}$, and it was found that EPMO converted in $44 \%$ to afford the corresponding poly(EPMO) in $30 \%$ yield. It seems that the activity of $\mathrm{PW}_{12}$ decreased by the coating of small amount of products on the surface of catalyst after the polymerization of EPMO. To revive the activity of catalyst, $\mathrm{PW}_{12 \text {-cycle }}$ was heated at $300^{\circ} \mathrm{C}$ for $3 \mathrm{~h}$ under open air. Then, the resulting catalyst $\mathrm{PW}_{12 \text {-heat }}$ was used again for the reaction of EPMO under same condition, and it was found that EPMO converted in quantitatively, affording the corresponding poly(EPMO) with $M_{\mathrm{n}}=11600, M_{\mathrm{w}} / M_{\mathrm{n}}=2.5$ in $77 \%$ yield. These results are summarized in Table II. In addition, the IR spectroscopy of $\mathrm{PW}_{12 \text {-heat }}$ was same to that of $\mathrm{PW}_{12 \text {-com. }}$.

\section{Cationic Isomerization of AOEO: The Reaction of AOEO with $\mathbf{P W}_{12 \text {-com. }}$ PW 12 -dry270, and $\mathbf{P W}_{12 \text {-vapor }}$}

As described in the introduction, Motoi reported ${ }^{16-21}$ the synthesis of bicyclo ortho ester by the isomerization of oxetane
Table II. The reaction of EPMO using $\mathrm{PW}_{12 \text {-cycle }}$ and $\mathrm{PW}_{12 \text {-heat }}$ as catalysts ${ }^{\mathrm{a}}$ )

\begin{tabular}{cccccc}
\hline Run & Catalyst & $\begin{array}{c}\text { Conversion }^{\mathrm{b})} \\
(\%)\end{array}$ & $\begin{array}{c}\text { Yield }^{\mathrm{c})} \\
(\%)\end{array}$ & $M_{\mathrm{n}}{ }^{\mathrm{d})}$ & $M_{\mathrm{w}} / M_{\mathrm{n}}{ }^{\mathrm{d})}$ \\
\hline 1 & $\mathrm{PW}_{12-\text { cycle }}$ & 44 & 30 & 10900 & 1.9 \\
2 & $\mathrm{PW}_{12 \text {-heat }}$ & $>99$ & 77 & 11600 & 2.5 \\
\hline
\end{tabular}

a) The reaction conditions: EPMO $(4 \mathrm{mmol})$, catalyst $(0.1 \mathrm{wt} \%)$, in chlorobenzene $(4 \mathrm{~mL})$ at $80^{\circ} \mathrm{C}$ for $12 \mathrm{~h}$. ${ }^{\text {b) }}$ Calculated by ${ }^{1} \mathrm{H}$ NMR.

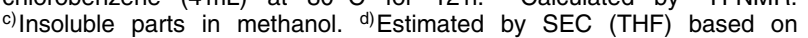
polystyrene standards.

Table III. The reaction of AOEO using $\mathrm{PW}_{12 \text {-com }}, \mathrm{PW}_{12-\text { dry270, }}$ and $\mathrm{PW}_{12 \text {-vapor }}$ as catalysts ${ }^{\mathrm{a}}$

\begin{tabular}{cccccc}
\hline & & \multicolumn{4}{c}{ Yield } \\
\cline { 3 - 6 } Run & Catalyst & BOE & Diol & Triol & Diester \\
\hline 1 & $\mathrm{PW}_{12 \text {-com }}$ & 68 & 2 & 0 & 0 \\
2 & $\mathrm{PW}_{12 \text {-dry270 }}$ & 70 & 0 & 0 & 0 \\
3 & $\mathrm{PW}_{12 \text {-vapor }}$ & 20 & 2 & trace & trace \\
\hline
\end{tabular}

a) The reaction conditions: AOEO $(8 \mathrm{mmol})$, catalyst $(0.1 \mathrm{wt} \%)$, in chlorobenzene $(8 \mathrm{~mL})$ at $80^{\circ} \mathrm{C}$ for $12 \mathrm{~h}$.

containing ester moiety such as AOEO using Lewis acid catalyst. In this case, cationic ring-opening polymerization did not proceed and only isomerization proceeded due to its neighboring effect of ester moiety. We also examined the cationic isomerization reaction of $\mathrm{AOEO}$ using $\mathrm{PW}_{12 \text {-com. }}$ and $\mathrm{PW}_{12-\text { dry270 }}$ as catalysts in chlorobenzene at $80^{\circ} \mathrm{C}$ for $12 \mathrm{~h}$. In the case of $\mathrm{PW}_{12 \text {-com. }}$ AOEO converted to produce bicyclo ortho ester 4-ethyl-1-methyl-2,6,7-trioxa-bicyclo[2.2.2]octane (BOE) and 2-hydroxymethyl-2-acethyloxymethyl-1-butanol (diol) in $68 \%$ and $2 \%$ yields, respectively. The obtained products were isolated by HPLC and their structures were confirmed by IR and ${ }^{1} \mathrm{H}$ NMR spectroscopy. Only BOE was obtained in $70 \%$ yield using $\mathrm{PW}_{12 \text {-dry270 }}$ as a catalyst. This

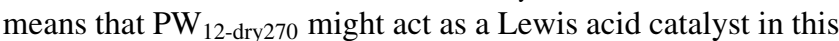




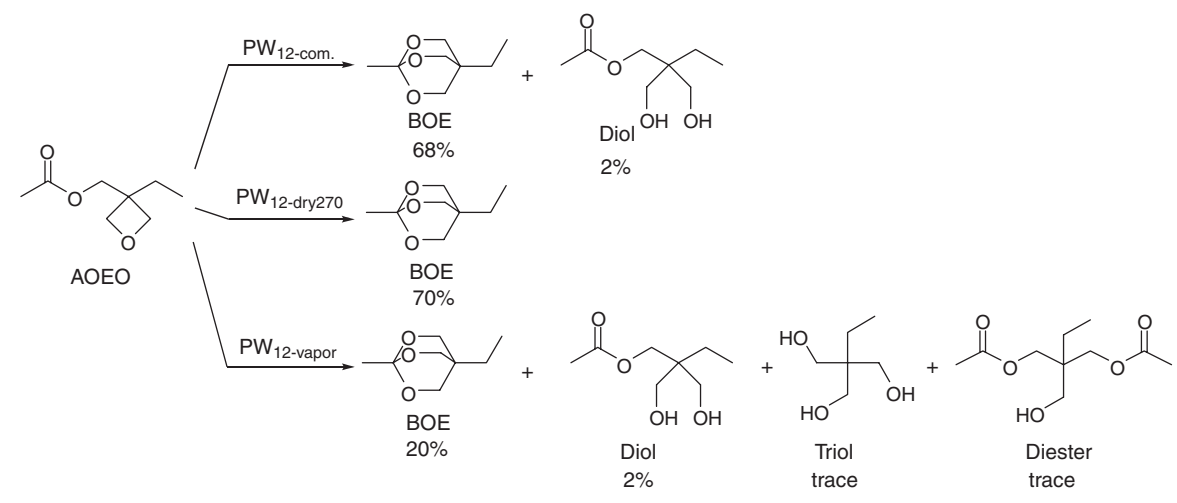

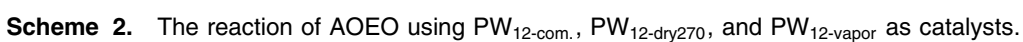

reaction system. Furthermore, we examined this cationic isomerization using $\mathrm{PW}_{12 \text {-vapor }}$ as a catalyst, and it was found that BOE and diol were obtained in 20 and $2 \%$ yields accompany with small amount of 1,1,1-trihydroxymethylpropane (triol) and 2,2-di(acethyloxymethyl)-1-propanol (diester) as shown in Scheme 2. However, in the all cases, no polymer was obtained. Consequently, $\mathrm{PW}_{12 \text {-dry270 }}$ is the most suitable catalyst for the cationic isomerization of oxetane.

All these results suggest that $\mathrm{PW}_{12 \text {-dry270 }}$ act as a Lewis acid to produce only BOE. However, no reaction of EPMO was observed using $\mathrm{PW}_{12-\mathrm{dry} 270}$ as a catalyst. That is, the cationic ring-opening polymerization was performed using $\mathrm{PW}_{12 \text {-com. }}$ and $\mathrm{PW}_{12 \text {-vapor }}$ due to their Brønstead acid active sites. It is also suggested that diol, triol, and diester were obtained by the hydrolysis or ester-exchange reaction of AOEO and resulting products with Brønstead acid active sites of $\mathrm{PW}_{12 \text {-com. }}$ and $\mathrm{PW}_{12 \text {-vapor }}$.

\section{CONCLUSIONS}

We examined the reaction behavior of two oxetanes such as EPMO and AOEO with heteropolyacids $\left(\mathrm{PW}_{12}\right)$ as cataionic catalysts. The reaction of oxetanes was examined using the commercial grade $\mathrm{PW}_{12}$ ( $\mathrm{PW}_{12 \text {-com. }}$ ), and anhydrous $\mathrm{PW}_{12}$ such as $\mathrm{PW}_{12 \text {-dry200 }}$ and $\mathrm{PW}_{12 \text {-dry270. As the result, it was found that }}$ $\mathrm{PW}_{12-\mathrm{com}}$ acts as a cationic catalyst for the ring-opening polymerization of EPMO at high reaction temperature $\left(80^{\circ} \mathrm{C}\right)$ to afford the corresponding poly(EPMO) in satisfactory yield. However, $\mathrm{PW}_{12 \text {-dry270 }}$ do not act as a cationic catalyst for the polymerization of EPMO. On the other hand, the isomerization reaction of $\mathrm{AOEO}$ proceeded using $\mathrm{PW}_{12 \text {-dry270 }}$ to give bicyclo ortho ester in high yield.

Received: April 1, 2008 Accepted: May 20, 2008 Published: July 16, 2008

\section{REFERENCES}

1. R. Neumann, Prog. Inorg. Chem., 47, 317 (1998).

2. M. Misono, Catal. Rev. Sci. Eng., 29, 269 (1987).
3. I. V. Kozhevnikov, Catal. Rev. Sci. Eng., 37, 311 (1995).

4. K. Bednarek, K. Brzezinska, J. Stasinski, P. Kubisa, and S. Penczek, Macromol. Chem., 190, 929 (1989).

5. A. Aoshima, S. Tonomura, and S. Yamamatsu, Polym. Adv. Technol., 2, 127 (1989).

6. S. Inoue and T. Aida, in "Ring-Opening Polymerization," K. J. Ivin and T. Saegusa, Ed., Elsevier Applied Science Publishers, London, Great Britain, Chapter 4, 1984, vol. 1, p 185.

7. M. P. Dreyfuss, "Oxetane Polymers in Encyclopedia of Polymer Science and Engineering," 2nd ed., H. F. Mark, N. M. Bikales, C. G. Oververger, and G. Menges, Ed., John Wiley and Sons, New York, 1987, p X/653 ff.

8. S. Penczek and P. Kubisa, "Cationic Ring-opening polymerization: Ethers in Comprehensive Polymer Science," G. Allen, Ed., Pergamon Press, Oxford, 1989, p III/751 ff.

9. H. Desai, "Telechelic Polyoxetanes in Polymeric Materials Encyclopedia,” J. C. Salamone Ed., CRC Press, New York, 1996, p XI/8268 ff.

10. E. J. Vandenberg, J. C. Mullis, and R. S. Juvet, J. Polym. Sci., Part A: Polym. Chem., 27, 3083 (1989).

11. E. J. Vandenberg, J. C. Mullis, R. S. Juvet, T. Millier, and R. A Nieman, J. Polym. Sci., Part A: Polym. Chem., 27, 3113 (1989).

12. H. Magnusson, E. Malmstron, and A. Hult, Macromolecules, 34, 5786 (2001).

13. O. Moriya, S. Yamamoto, T. Sugizaki, J. Maeda, A. Kamejima, T. Kumon, and T. Kageyama, Polym. J., 37, 262 (2005).

14. H. Magnusson, E. Malmstron, A. Hult, and M. Johansson, Polymer, 43, 301 (2002).

15. Y. Chen, M. Bednarek, P. Kubisa, and S. J. Penczek, J. Polym. Sci., Part A: Polym. Chem., 40, 1991 (2002).

16. H. Ogawa, S. Kanoh, and M. Motoi, Bull. Chem. Soc. Jpn., 70, 1649 (1997).

17. S. Kanoh, T. Nishimura, K. Ando, H. Ogawa, and M. Motoi, Macromolecules, 31, 7988 (1998).

18. S. Kanoh, T. Nishimura, H. Senda, H. Ogawa, and M. Motoi, Macromolecules, 32, 2438 (1999).

19. S. Kanoh, T. Nishimura, Y. Kita, H. Ogawa, M. Motoi, M. Takani, and T. Tanaka, J. Org. Chem., 65, 2253 (2000).

20. S. Kanoh, T. Nishimura, T. Tsuchida, H. Senda, M. Motoi, M. Takani, and N. Matsuura, Macromol. Chem. Phys., 202, 2489 (2001).

21. A. Ueyama, M. Mizuno, S. Kanoh, and M. Motoi, Polym. J., 34, 944 (2002).

22. Y. Chen, Z. Chen, G. Zhang, and H. Zhang, Acta Polym. Sinica., 4, 506 (2000).

23. T. Nishikubo, A. Kameyama, M. Ito, and A. Suzuki, J. Polym. Sci., Part A: Polym. Chem., 36, 2873 (1998).

24. T. Endo, M. Okawara, and W. J. Baily, Polym. J., 13, 715 (1981).

25. Y. Yamashita, T. Asakura, M. Okada, and K. Ito, Macromolecules, 2 , 613 (1969). 